\title{
Indo-European and Asian origins for Chilean and Pacific chickens revealed by mtDNA
}

\author{
Jaime Gongora*†, Nicolas J. Rawlence ${ }^{\ddagger}$, Victor A. Mobegi§, Han Jianlin§币, Jose A. Alcalde\|, Jose T. Matus", \\ Olivier Hanotte§, Chris Moran*, Jeremy J. Austin*, Sean Ulm**, Atholl J. Anderson ${ }^{\dagger \dagger}$, Greger Larson ${ }^{\ddagger \ddagger \S \S, ~}$ \\ and Alan Cooper

\begin{abstract}
*Centre for Advanced Technologies in Animal Genetics and Reproduction, Faculty of Veterinary Science, University of Sydney, Sydney NSW 2006, Australia; ${ }^{\ddagger}$ Australian Centre for Ancient DNA, School of Earth and Environmental Sciences, University of Adelaide, Adelaide SA 5005, Australia; §International Livestock Research Institute, P.O. Box 30709, Nairobi 00100, Kenya; "Joint Laboratory on Livestock and Forage Genetic Resources, Institute of Animal Science, Chinese Academy of Agricultural Sciences, Beijing 100094, China; IFacultad de Agronomia e Ingenieria Forestal, Pontificia Universidad Catolica de Chile, Casilla 306-22 Santiago, Chile; **Aboriginal and Torres Strait Islander Studies Unit, University of Queensland, Brisbane QLD 4072, Australia; ${ }^{\ddagger \ddagger}$ Department of Archaeology, Durham University, South Road, Durham DH1 3LE, United Kingdom; §§Department of Medical Biochemistry and Microbiology, Uppsala University Biomedical Center, Box 597, 751 24 Uppsala, Sweden; and ${ }^{+\dagger}$ Department of Archaeology and Natural History, Research
\end{abstract} \\ School of Pacific and Asian Studies, Australian National University, Canberra ACT 0200, Australia
}

Edited by Joyce Marcus, University of Michigan, Ann Arbor, MI, and approved May 7, 2008 (received for review February 29, 2008)

European chickens were introduced into the American continents by the Spanish after their arrival in the 15th century. However, there is ongoing debate as to the presence of pre-Columbian chickens among Amerindians in South America, particularly in relation to Chilean breeds such as the Araucana and Passion Fowl. To understand the origin of these populations, we have generated partial mitochondrial DNA control region sequences from 41 native Chilean specimens and compared them with a previously generated database of $\approx 1,000$ domestic chicken sequences from across the world as well as published Chilean and Polynesian ancient DNA sequences. The modern Chilean sequences cluster closely with haplotypes predominantly distributed among European, Indian subcontinental, and Southeast Asian chickens, consistent with a European genetic origin. A published, apparently pre-Columbian, Chilean specimen and six pre-European Polynesian specimens also cluster with the same European/Indian subcontinental/Southeast Asian sequences, providing no support for a Polynesian introduction of chickens to South America. In contrast, sequences from two archaeological sites on Easter Island group with an uncommon haplogroup from Indonesia, Japan, and China and may represent a genetic signature of an early Polynesian dispersal. Modeling of the potential marine carbon contribution to the Chilean archaeological specimen casts further doubt on claims for pre-Columbian chickens, and definitive proof will require further analyses of ancient DNA sequences and radiocarbon and stable isotope data from archaeological excavations within both Chile and Polynesia.

Araucana chicken | Gallus gallus | pre-Columbian chicken | control region

$\mathbf{T}^{\mathrm{s}}$ he presence of chickens in the American continents has traditionally been attributed to the Spanish introduction of European chickens after their arrival in the 15 th century. However, there is still debate about whether Amerindians in South America possessed chickens before the arrival of the Spanish, particularly in relation to several unusual Chilean breeds. For example, the Araucana breed is thought to be descended from indigenous Amerindian chickens and is unusual in that it lays blue/green-shelled eggs and possesses distinctive plumage patterns. Three groups or variants of Araucana are currently recognized: ketros (ear-tufted and normal tailed), kolloncas (nontufted and rumpless), and kollonca de aretes (ear-tufted and rumpless). Because these features are also found among Asian rather than Mediterranean chickens, it has been hypothesized that the Araucana breed might have an Asian origin. A similar origin has been suggested for another historic Chilean breed, the Passion Fowl.

Potential sources for the pre-Columbian introduction of chickens include early Polynesian or Dutch traders on the Pacific coast of South America (1-3). However, there has been no detailed genetic analysis of these so-called "Amerindian" chickens to investigate the potential contribution of Asian or European breeds, although a short mitochondrial DNA control region (mtDNA CR) sequence was recently reported from two feathers of potential Araucana origin along with a Chilean archaeological specimen (El Arenal-1) apparently dating to a time immediately preceding the Columbian period Cal AD 1304-1424 (4). The latter sequence was linked to other chicken sequences from several Polynesian archaeological sites in an analysis that included only a limited number of other comparative sequences and was used as support of pre-Columbian trading contact between Polynesians and South American Amerindians.

A previous phylogenetic study of the chicken mtDNA CR suggested that the Indochinese Red Junglefowl subspecies Gallus gallus gallus is the primary maternal ancestor of the domestic chicken (Gallus gallus domesticus) and that Southeast Asia was a likely center of domestication (5). A subsequent study analyzed an expanded mtDNA CR dataset in which nine divergent haplogroups were identified, seven of which consisted of both domestic chicken and Red Junglefowl subspecies (6). In contrast to the earlier study, this pattern suggested multiple centers of domestication across both Southeast Asia and the Indian subcontinent, consistent with archaeological studies $(7,8)$.

Three of the nine haplogroups or clusters [A, B, and E of Liu et al. (6)] contain mtDNA CR haplotypes from all over Eurasia, whereas the other haplogroups contain haplotypes mainly from southern and Southeast Asia. Haplogroups A, B, C, and E are relevant for this study because they contain the ancient and modern Chilean chicken sequences or provide insights into the mtDNA signatures of ancient Pacific chickens. Haplogroup E is predominant among Indian, Middle Eastern, and European chickens and is an indication that the roots of European chickens lie within the Indian subcontinent. The primary haplotype of this haplogroup, E1, is the single most-common chicken haplotype found around the world. Haplogroups A and B predominate among South and eastern Chinese and Japanese chickens as well as wild Red Junglefowl. Consequently, although chicken

Author contributions: J.G. and J.A.A designed research; J.G., V.A.M., H.J., J.A.A., J.T.M., and O.H. performed research; N.J.R. and S.U. contributed new reagents/analytic tools; J.G., N.J.R., V.A.M., H.J., O.H., and J.J.A. analyzed data; and J.G., C.M., A.J.A., G.L., and A.C. wrote the paper. The authors declare no conflict of interest. This article is a PNAS Direct Submission.

Data deposition: The sequences reported in this paper have been deposited in the GenBank database (accession nos. EF190830-EF190870).

†To whom correspondence should be addressed. E-mail: j.gongora@usyd.edu.au.

This article contains supporting information online at www.pnas.org/cgi/content/full/ 0801991105/DCSupplemental.

C 2008 by The National Academy of Sciences of the USA 


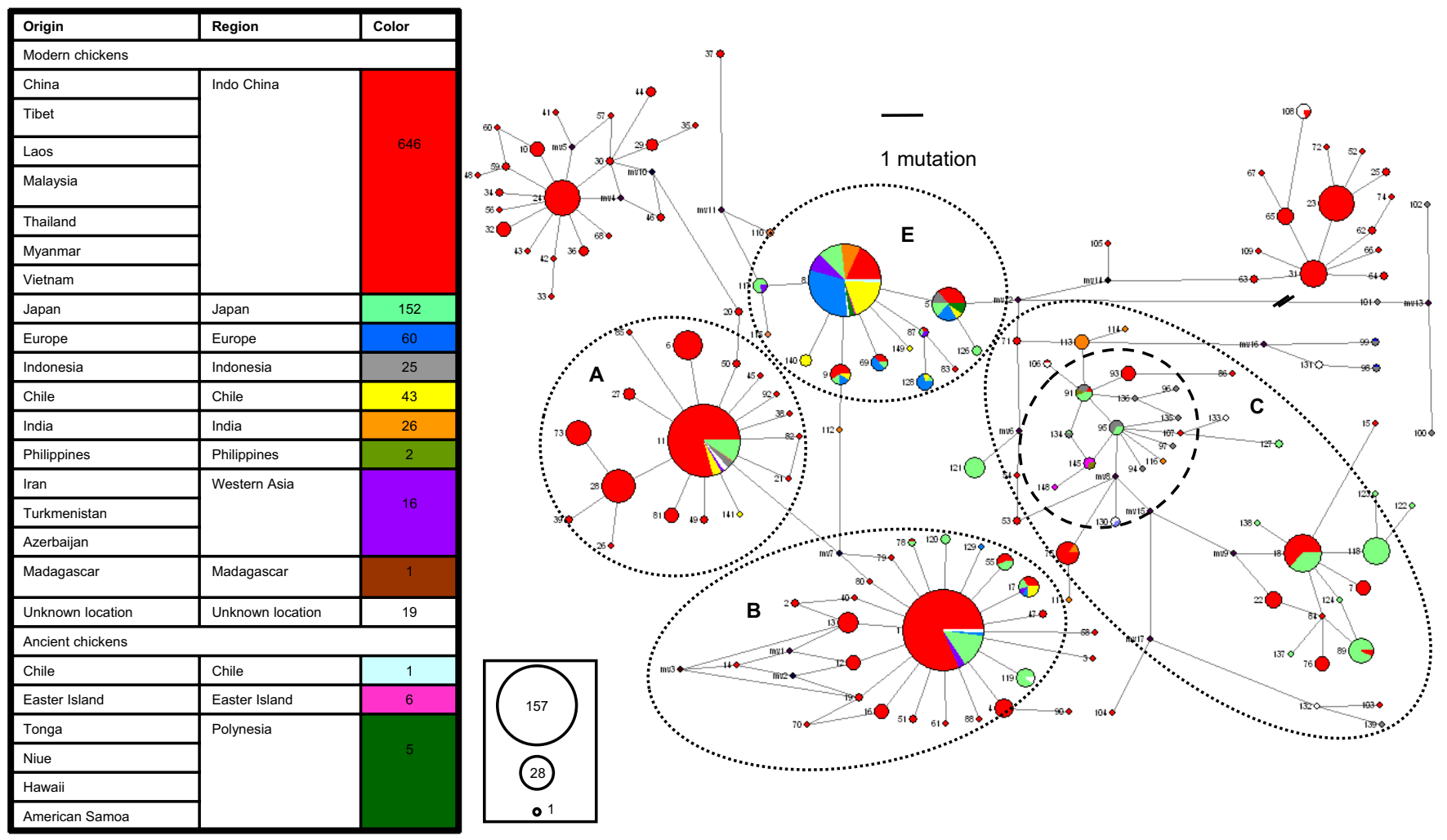

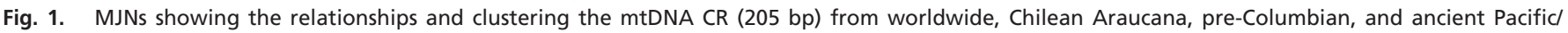

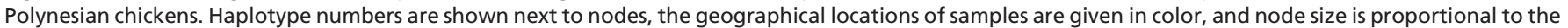

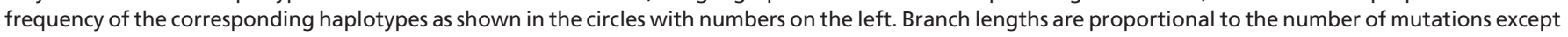

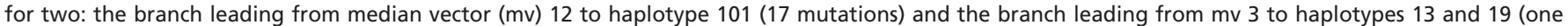

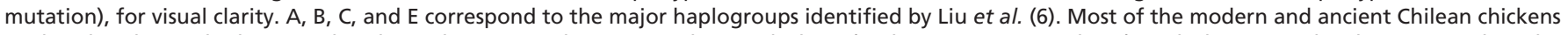

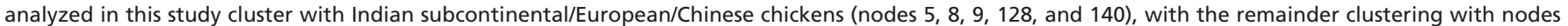

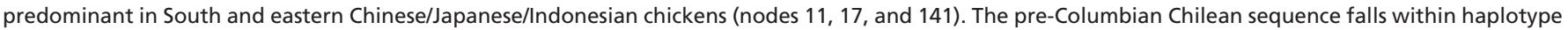

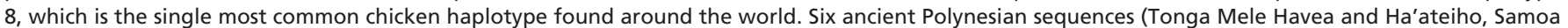

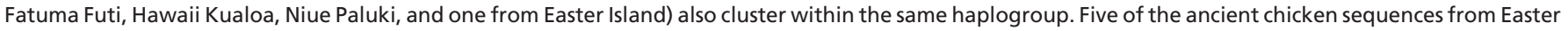

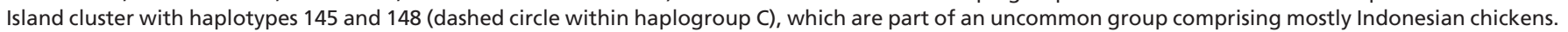
The Easter Island sequences may represent mtDNA signatures of early Polynesian chicken transport.

mtDNA sequences do not show the strict phylogeographic patterns observed in other domestic animals in the region, such as pigs (9), the majority of haplogroups do exhibit some form of restricted distribution on subcontinental scales. Specific haplotypes within these haplogroups however, such as E1 and A1 (equivalent to haplotypes 8 and 11, respectively, in Fig. 1) are present at high frequencies within chicken breeds and populations all over the world. Haplogroup $\mathrm{C}$ is found mainly in Japanese and southeastern Chinese chickens (6) and contains a subcluster of southern Japanese natives from the island of Okinawa found to be closely related to Indonesian native chickens (10).

To further investigate the potential Polynesian-Chilean genetic links, we generated mtDNA CR sequences from 41 modern Chilean chickens and analyzed their phylogenetic relationships with a large database of $\approx 1,000$ sequences, including those described by Liu et al. (6) and available in ancient mtDNA CR sequences from Chile and the Pacific islands (4). In addition, we modeled the potential impact of marine carbon contribution on the calibrated age of the pre-Columbian chicken bone from El Arenal-1, an analysis not undertaken by Storey et al. (4). It is important to note that this specimen was from a near-coastal site and dated only 70 years before initial Spanish contact and that samples including material derived from marine environments can exhibit older apparent radiocarbon ages because of the uptake of carbon that has already undergone radioactive decay through long residence times in the deep ocean. Studies of marine reservoir effects $(\Delta R)$ for Chile are limited, so we calibrated the age under several scenarios of marine carbon input.

\section{Results}

Phylogenetic Clustering of Modern Chilean Chickens. Seventeen polymorphic sites and eight haplotypes were identified among the modern Chilean chicken 530-bp CR sequences [supporting information (SI) Figs. S1 and S2], with 16 of these sites falling within the 205-bp region (Fig. S3). In contrast, Storey et al. (4) report only nine polymorphic sites within ancient and modern sequences across the same region because of the very limited number of sequences analyzed. Chilean haplotypes were named by using the haplotype numbers of the median-joining network (MJN, Fig. 1) analysis of the 205-bp sequence alignment (Fig. $\mathrm{S} 3$ ), followed by " $\mathrm{CH}$ " for Chile, as follows: 5-CH (number of samples, $n=2)$, 8-CH $(n=25), 9-\mathrm{CH}(n=1), 11-\mathrm{CH}(n=5)$, $17-\mathrm{CH}(n=2), 128-\mathrm{CH}(n=1), 140-\mathrm{CH}(n=4)$, and 141-CH $(n=1)$. Araucana chickens $(n=28)$ possess seven of the eight observed haplotypes, indicating a high genetic diversity, whereas in contrast, the same single haplotype $(8-\mathrm{CH})$ observed in 15 of these Araucana specimens is also shared by Passion Fowl $(n=$ $4)$, Creole $(n=5)$, and Chilean/Japanese Long Tail $(n=1)$ (Table S1). MJN analyses (Fig. 1) show that five of the Chilean chicken haplotypes $(5-\mathrm{CH}$, the very common $8-\mathrm{CH}, 9-\mathrm{CH}$, 
Table 1. Effect of increasing proportions of marine-derived carbon on calibration of directly dated El Arenal-1 chicken bone

\begin{tabular}{lclc}
$\Delta R$ & Marine C, \% & Calibration dataset & $\begin{array}{c}\text { Radiocarbon on chicken bones from } \\
\text { the El Arenal-1 }(n=622 \pm 35)\end{array}$ \\
\hline $0 \pm 0$ & 0 & SHCal04 & AD1304-1424 \\
$61 \pm 50^{*}$ & 10 & Mixed marine SoHem & AD1322-1445 \\
$61 \pm 50$ & 20 & Mixed marine SoHem & AD1395-1459 \\
$61 \pm 50$ & 30 & Mixed marine SoHem & AD1407-1501 \\
$61 \pm 50$ & 40 & Mixed marine SoHem & AD1430-1619 \\
$61 \pm 50$ & 50 & Mixed marine SoHem & AD1455-1630 \\
\hline
\end{tabular}

${ }^{*} \Delta R$ of $61 \pm 50$ based on single bivalve determination from Valparaiso, Chile (12). This value is considered a conservative estimate of depletion in these waters. All calibrated dates are reported at $2 \sigma$. Bold type denotes pre-Columbian values.

128- $\mathrm{CH}$, and $140-\mathrm{CH}$ ) cluster within a geographically widespread major haplogroup consisting of European, Middle Eastern, Indian, and Chinese domestic chickens (equivalent to haplogroup E, Liu et al.) (6). Of the other three Chilean haplotypes, 11- $\mathrm{CH}$ and 141- $\mathrm{CH}$ are found mainly in domestic chickens from South and eastern China, including wild Red Junglefowl and some Japanese and Indonesian chickens. The last haplotype, $17-\mathrm{CH}$, recovered from one Araucana and one creole chicken, is a sequence found mainly in Chinese and Japanese chickens. One of the two modern Araucana feather sequences generated by Storey et al. (4) also belonged to haplotype 17. The other feather sequence corresponds to a unique haplotype 149 . However, there was insufficient information to assess whether these two specimens indeed originated from the Araucana breed.

Maximum parsimony (MP) and MJN analyses gave similar topologies [Fig. 1, and Figs. S4-S7], with minor differences from Liu et al. (6) because of the different phylogenetic approaches and because several sequences collapsed into single haplotypes within the shorter (205 bp) alignment.

Phylogenetic Position of Archaeological Pacific and Pre-Columbian Chickens. The single ancient sequences reported from Tonga Mele Havea and Ha'ateiho, Samoa Fatuma Futi, Hawaii Kualoa, Niue Paluki, one sequence from Easter Island Anakena (early settlement phase Cal AD 1270-1400), and the putatively preColumbian (Cal AD 1304-1424) Chilean El Arenal-1 sequence belong to haplotypes 8 and 5 within haplogroup E (Fig. 1). Haplotype 8 equates to the E1 haplotype reported in Liu et al. (6), which is ubiquitous worldwide and $100 \%$ identical to haplotypes from European Barred Plymouth Rock, White Plymouth Rock, White Leghorn. and New Hampshire as well as native chicken sequences from Africa, India, Central Asia, and China. In contrast, five of the other contemporaneous archaeological chicken sequences from Easter Island cluster with haplotypes $145(n=4)$ and $148(n=1)$, which are part of an uncommon group comprising mostly Indonesian chickens within haplogroup C (Fig. 1). Ancient Easter Island haplotype 145 is identical to one sequence of Red Junglefowl from the Philippines (11). Within other modern chickens, the closest related sequences have been recorded from Lombok and Java in Indonesia and the Philippines. Given their unique phylogenetic position and their preEuropean contact dates, haplotypes 145 and 148 presumably represent a record of early Polynesian chicken transport, potentially overwritten subsequently in the western Pacific. The noticeably less star-like pattern of haplogroup $\mathrm{C}$, centered on the less frequent haplotypes 91 and 95, is likely to be an artifact of incomplete sampling or a different population history.

Marine Carbon Contribution to Calibrate the Date of a Chicken Bone from El Arenal-1. The directly dated chicken bone from El Arenal-1 reported by Storey et al. (4) was calibrated by using different estimates of marine reservoir effects for the Chilean coast (12-14). A conservative value of $\Delta R=61 \pm 50$ and a slightly more depleted $\Delta R=154 \pm 131$ (which represents the weighted mean of the $\Delta R=61 \pm 50$ from Valparaiso and $\Delta R=$ $243 \pm 49$ from northern Peru) were used to calibrate the date $(15,16)$, along with different proportions of marine-derived carbon. When either $\Delta R$ value is used, the carbon content would need to be $<20 \%$ derived from marine pathways to securely date it before AD 1500 (Table 1 and Table S2). However, a marine carbon contribution of $>20 \%$ would be consistent with a postColumbian date.

\section{Discussion}

mtDNA Signatures Do Not Support a Polynesian Origin for PreColumbian Chicken. The position of the single Chilean preColumbian chicken sequence within the worldwide distributed haplotype 8 removes any genetic support for a Polynesian introduction of this haplotype to South America. This haplotype is likely to have been common in chickens introduced by the Spanish in the 15 th century as well as European breeds transported during subsequent colonial era trade.

Five of the six archaeological Easter Island sequences are part of an uncommon, closely related cluster of haplotypes within haplogroup $\mathrm{C}$, which is centered in the Indonesian islands (eastern and western Java, West Sumatra, and Lombok Island) with a few representatives in Japan and the Philippines, but which has not yet been detected elsewhere in Polynesia (4). The ancient Easter Island specimens are clearly pre-European according to both radiocarbon dating and stratigraphy, indicating that this haplotype must form part of the original "Polynesian/ Pacific" chicken dispersal, which has potentially been erased across the western Polynesian islands by replacement or introgression by haplotypes 5 and 8 (Fig. 1). Because Easter Island is commonly suggested as the key site to facilitate contact between Polynesian and South American cultures, it is significant that the common Easter Island haplotypes do not appear to have reached South America or have not survived into the modern day if they did so.

This scenario is analogous to the history of domestic pigs in Europe (17) and bottle gourds in the New World (18). In the first study, Neolithic domestic pigs in Europe were shown to be derived from Near Eastern wild boar, but were subsequently replaced by domestic pigs derived from European wild boar (17). In the case of the bottle gourd, although all modern American samples demonstrated a genetic affinity with Africa (19), DNA from ancient samples revealed that the first bottle gourds to enter the Americas did so, not across the Atlantic, but via Asia (18). This shifting temporal pattern indicates that the original lineages of domestic plants and animals introduced into a new area can often be replaced by later introductions of the same domestic species with a different genetic heritage, thus erasing 
the evidence of the initial dispersal. Depending on the degree to which the legacy of the initial introductions has been erased, studies of modern samples may be capable of detecting only the most recent introduction.

In this context, archaeological sequences from Chile, Hawaii, Niue, Tonga, and American Samoa fall within at least two of the widespread European/Indian subcontinental/Chinese haplogroups, suggesting that at least four haplotypes (Fig. 1, haplotypes 5, 8, 145, and 148) can be considered part of Pacific/ Polynesian chicken dispersals. It is possible that these dispersals were not contemporaneous, in which case the European/Indian subcontinental/Chinese haplotypes may have formed a more recent wave of dispersals, overwriting and removing the earlier Indonesian sequences across western Polynesia but failing to do the same in distant Easter Island. However, it is also important to note that standard European/Indian subcontinental/Chinese haplotypes such as 8 would result if either the specimens or laboratory procedures were contaminated with any amount of modern chicken DNA. The contamination of laboratory consumables is a well known problem when working with ancient samples of domestic species (20), which tend to be widespread but not genetically diverse.

Marine Carbon Input and the Presence of Pre-Columbian Chickens. As a consequence of the phylogenetic analyses, the evidence for pre-Columbian chickens in South America depends on the quality of the radiocarbon dates and calibration of the El Arenal-1 specimen (Cal AD 1304-1424) reported in Storey et al. (4). Importantly, this date was not corrected for possible marine carbon offset, presumably because of the high $\delta^{13} \mathrm{C}$ value $(21 \%)$ (4). Although it is known that $\delta^{13} \mathrm{C}$ values for chickens, like other birds, are strongly controlled by diet, the relationship between carbon isotopic fractionation and the metabolic process in chickens is poorly understood $(21,22)$, masking the potential contributions of marine and terrestrial sources to the isotopic signature of chicken bones (23). As omnivores, chickens consume a wide range of materials available in their local environment, including fish, shellfish, and other marine-derived materials in coastal areas. Marine shell grit, for example, is often ingested by chickens and other birds to assist digestion and provide minerals to the diet $(24,25)$. In the case of El Arenal-1, consumption of marine foods is especially likely because of the close proximity of the coast $(<3 \mathrm{~km})$ and the apparent stratigraphic association of recovered chicken remains with marine shellfish, fish, and marine birds, suggesting the ready availability of materials deriving from marine environments to the chicken $\operatorname{diet}(26)$.

On average, the surface ocean reservoir $(<200 \mathrm{~m})$ has an apparent ${ }^{14} \mathrm{C}$ age $\approx 400$ years older than the atmospheric reservoir (27). Variation in ${ }^{14} \mathrm{C}$ activity in marine environments, although related to changes in atmospheric activity, depends greatly on local and regional factors, such as rates of mixing of surface waters with upwelled ${ }^{14} \mathrm{C}$-depleted deep ocean waters, hinterland geology, tidal flushing, and terrestrial water input. Such factors are highly variable and can introduce uncertainties of up to several hundred years into dates obtained on marine samples in some parts of the world. Although accurate measurements for El Arenal-1 are lacking, recent estimates of the marine reservoir effect along the Chilean coast are conservatively estimated at $\Delta R=61 \pm 50$ and the site itself is characterized by large shell middens (A.J.A., unpublished work).

Consequently, if the diet of the El Arenal-1 chicken included a marine carbon contribution of $>20 \%$, the calibrated age would be post-Columbian. Examination of a large number of specimens of several species at the site, including studies of $\delta^{13} \mathrm{C}, \delta^{15} \mathrm{~N}$, and $\delta^{34} \mathrm{~S}$, will be necessary to evaluate the contribution of marine carbon to the omnivorous chicken diet $(28,29)$. It is also worth noting that the radiocarbon-dating laboratory used to date the El
Arenal-1 sample has recently been suggested to have overestimated the age of zooarchaeological bones elsewhere in the Pacific (30). The uncertainty of the marine carbon contribution and accuracy of the date indicates that further analyses are needed to definitively identify them as pre-Columbian.

Multiple mtDNA Origins of the Modern Araucana Chicken. The high percentage of European chickens $(>91 \%)$ sharing haplotypes with the Indian subcontinent suggests that the latter was the main source for chickens introduced into Europe. As a result, we consider the clustering of the modern Chilean chicken sequences with haplotypes predominant in Europe to indicate the contribution of Spanish introduced chickens. In the light of our analyses, it would be controversial to use the single preColumbian sequence (or indeed any haplotype from the European/Indian subcontinental/ Chinese haplogroups) as evidence for a Southeast/eastern Asian or Pacific origin for the Araucana, as claimed by Storey et al. (4).

At present, there is certainly no evidence to support an ancient Asian Pacific route for the introduction of Indian subcontinental/European/Chinese chicken haplotypes into Chile. It is possible that the few Araucana sequences that cluster with haplotypes predominant in southern and eastern China, Indonesia, and Japan could result from a pre-Columbian Asian introduction, but it would appear much more likely to represent modern introgression of Asian mtDNA genes into the South American populations. If ancient Pacific/pre-Columbian chickens were the ancestors of the Araucana, traits such as blue/green-shells, ear-tufts, and/or rumples might be expected to occur in some modern Pacific Island chickens. However, we are unable to find any reports that this is the case.

In conclusion, the archaeological Pacific and Chilean preColumbian chicken sequences fall among a widespread European/ Indian subcontinental/Chinese haplogroup and provide no support for Polynesian-South American contact. Four haplotypes have been detected in Polynesian archaeological material, but the only unique sequences are those from Easter Island that appear to originate in Island Southeast Asia. None of these Easter Island haplotypes have been detected in either ancient or modern South American breeds. Three major maternal lineages have contributed to the modern Chilean chicken breeds, mainly from the European/Indian subcontinental region but also in low frequency from the South Chinese/ Indonesian/Japanese area. In addition, the lack of information about the marine carbon input for the chicken bones from $\mathrm{El}$ Arenal-1 leaves the pre-Columbian date uncertain. The identification of diagnostic markers for Asian and Mediterranean traits in combination with mtDNA, female-specific $\mathrm{W}$ chromosome and microsatellite markers will be required to resolve the timing and nature of introductions, modern diversity and regional adaptation of local chicken breeds in the Americas and Island South East Asia. Of particular interest will be chickens kept by some indigenous communities in the Amazon forest, the origins of which remain unclear.

\section{Materials and Methods}

Chicken Samples, PCR, and Sequencing. Blood samples were obtained from 41 modern Chilean chickens including 28 Araucanas (ketros, kolloncas, kollonkas de aretes), 7 creole, 1 Japanese Long Tail and 5 Passion Fowl from 12 locations in Chile. The authenticity of the Araucana specimens was assessed by J.A.A., an international authority on this breed. The voucher information and identification number of the DNA samples used in this study are supplied in Table S1. DNA was precipitated and extracted by using a salting-out method (31) at the Pontificia Universidad Catolica de Chile. PCR and sequencing procedures were conducted at the International Livestock Research Institute (Kenya). Primer pairs (5'-AGGACTACGGCTTGAAAAGC-3' and 5'-ATGTGCCTGACCGAGGAACCAG-3') were used to amplify $\approx 600 \mathrm{bp}$ of the mitochondrial hypervariable 1 region. $\mathrm{PCR}$ was performed in $30-\mu \mathrm{l}$ reaction volumes containing $50 \mathrm{mM} \mathrm{KCl}$ $10 \mathrm{mM}$ Tris $\cdot \mathrm{HCl}$ (pH 8.3), $0.1 \%$ Triton X-100, $1.5 \mathrm{mM} \mathrm{MgCl}_{2}, 0.2 \mathrm{mM}$ dNTPs, 0.1 $\mu \mathrm{M}$ concentrations of each primer, 1.25 units of TaqDNA polymerase (Pro- 
mega), and 100-200 ng of template DNA. PCR conditions included an initial denaturation at $94^{\circ} \mathrm{C}$ for $2 \mathrm{~min}$, followed by 35 cycles of $25 \mathrm{~s}$ at $94^{\circ} \mathrm{C}, 35 \mathrm{~s}$ at $58^{\circ} \mathrm{C}$, and $1 \mathrm{~min} 10 \mathrm{~s}$ at $72^{\circ} \mathrm{C}$, and a final extension for $10 \mathrm{~min}$ at $72^{\circ} \mathrm{C}$. PCR products were purified by using the QIAQuik PCR purification kit (Qiagen) and directly sequenced by using two internal primers CR for (5'-TCTATATTCCACATTTCTC-3') and CR-Rev (5'-GCGAGCATAACCAAATGG-3') on an ABI 3730. Forward and reverse sequences were overlapped to obtain a consensus sequence of $530 \mathrm{bp}$ for each sample, after excluding primer sequences. To avoid PCR artifacts, two independent PCRs were used to amplify the mtDNA sequence from all specimens.

Phylogenetic Analyses. In the Storey et al. (4) study, a phylogenetic analysis was not performed, and 9 SNPs were simply contrasted between specimens. Furthermore, the analysis did not include extensive mtDNA CR datasets available on GenBank from native and modern chicken breeds and Red Junglefowl. To perform a detailed phylogenetic analysis, ClustalW (32) was used to align the 41 Chilean chicken mtDNA CR sequences with a large mtDNA CR dataset of $\approx 950$ sequences including those from Liu et al. (6) and Oka et al. (10). The alignment included sequences from European Barred Plymouth Rock (GenBank accession no. AB007719), White Plymouth Rock (AP003318), White Leghorn (AP003317 and D82920), and New Hampshire chickens (AY235571) (33). Two aligned datasets were generated; the first consisted of 534 bp (990 sequences) and the second a truncated version of $205 \mathrm{bp}$ (1,003 sequences) including indels (insertions/deletions). The shorter dataset was limited to the sequence lengths of the ancient Pacific and pre-Columbian chickens that were $169-201 \mathrm{bp}$ [not $\approx 400 \mathrm{bp}$ as stated in Storey et al. (4)] to facilitate phylogenetic comparisons of these specimens. The two aligned datasets were reduced to unique haplotypes by using FaBOX (www.birc.au.dk/fabox), exported as aligned FASTA files, and converted into Nexus format by using MEGA 3.1 (34) for network and phylogenetic analyses.

MJN analyses were performed by using Network 4.1.1.2 (35). The original 534-bp aligned dataset was used to generate a multistate alignment rdf (Roehl data format) file of variable positions along with the frequency per haplotype and phylogenetic weight for each variable position (Figs. S2 and S3), which was imported into Network 4.1.1.2. The impact of down weighting sites that are apparent mutational hotspots or that exhibit high levels of conflict within Network analyses was investigated. Sites observed to mutate $>10$ times within a network were given a weighting score of 0.0 (ignored in the analysis) in the rdf file, whereas sites that mutated more than five times were down weighted to 0.2 , by using standard settings within Network 4.1.1.2. This rdf multistate alignment file was star contracted (with a threshold connection limit of five) to further collapse very closely related sequences (e.g., star phylogenies/polytomies) into haplotypes. Network analysis was also performed on the shorter 205-bp alignment as described above by using down weighting of the same sites and without weighting or star contraction.

Phylogenetic analyses were attempted by using ML with the 534-bp datasets, but the very large number of closely related sequences generated mul-

1. Carter GF (1975) The chicken in America. Anthropol J Can 13:25-26.

2. Errázuriz J (2000) Cuenca del Pacífico: 4.000 Años de Contactos Culturales. Serie Divulgación. Santiago (Universidade de Santiago de Compostela, Santiago, Chile).

3. Ramirez JMA (2006) Cronologia y fuentes de la historia de Rapa Nui: 1722-1966. Rev Arch Hist Patrim Viña del Mar 7:185-209.

4. Storey AA, et al. (2007) Radiocarbon and DNA evidence for a pre-Columbian introduction of Polynesian chickens to Chile. Proc Natl Acad Sci USA 104:10335-10339.

5. Fumihito A, et al. (1996) Monophyletic origin and unique dispersal patterns of domestic fowls. Proc Natl Acad Sci USA 93:6792-6795.

6. Liu YP, et al. (2006) Multiple maternal origins of chickens: Out of the Asian jungles. Mol Phylogenet Evol 38:12-19.

7. West B, Zhou B-X (1988) Did chickens go north? New evidence for domestication. J Archaeol Sci 15:515-533.

8. Zeuner FE (1963) A History of Domesticated Animals (Hutchinson, London).

9. Larson G, et al. (2005) Worldwide phylogeography of wild boar reveals multiple centers of pig domestication. Science 307:1618-16121.

10. Oka T, et al. (2007) Analysis of mtDNA sequences shows Japanese native chickens have multiple origins. Anim Genet 38:287-293.

11. Nishibori M, Shimogiri T, Hayashi T, Yasue H (2005) Molecular evidence for hybridization of species in the genus Gallus except for Gallus varius. Anim Genet 36:367-375.

12. Ingram BL, Southon JR (1996) Reservoir ages in Eastern Pacific coastal and estuarine waters. Radiocarbon 38:573-582.

13. Reimer P, Reimer R (2008) Marine Reservoir Correction Database. http://calib.qub.ac.uk/marine/, accessed February 10, 2008.

14. Taylor RE, Berger R (1967) Radiocarbon content of marine shells from the Pacific coasts of Central and South America. Science 158:1180-1182.

15. Stuiver M, Reimer PJ (1993) Extended ${ }^{14} \mathrm{C}$ data base and revised CALIB $3.0{ }^{14} \mathrm{C}$ age calibration program. Radiocarbon 35:215-230.

16. Stuiver M, Reimer PJ, Reimer R (2005) CALIB Manual http://calib.qub.ac.uk/calib/ manual/, accessed March 31, 2006. tiple polytomies and unreliable bootstrap analyses. Consequently, MP was performed by using PAUP 4.0b10 (36), because MP is better suited than ML to missing sequence data/different length sequences in large datasets $(37,38)$. A strict consensus MP tree (Fig. S6) was constructed by using 20 independent runs with random starting points, the maximum number of trees saved set at 10,000 , a random addition of sequences, and the collapsing of all branches with a minimum length of zero to decrease internal branch rearrangements within star phylogenies. Two Red Junglefowl sequences (Gallus gallus gallus, AB007720, and Gallus gallus bankiva, AB007718) were used as outgroups.

Approximately 200,000 MP trees were generated, and the 30,276 mostparsimonious trees were used to construct a strict consensus tree. This was used to investigate the phylogenetic position of the short ancient Polynesian and Chilean chicken sequences by repeating the analysis but including these sequences and by using the strict consensus tree topology as a fixed phylogenetic constraint, with the random addition of sequences and collapsing branches with a minimum length of zero. Approximately 24,300 mostparsimonious trees were produced and used to construct a $50 \%$ majority-rule consensus tree. Bootstrap analysis was impractical because of the large dataset of very closely related sequences.

A description of polymorphic sites, haplogroups, and network analyses are included in Tables S1 and S3 and Fig. S1. The full 534-bp alignment contained 125 polymorphic sites, whereas the truncated alignment ( $205 \mathrm{bp}$ ) contained just 81 polymorphic sites, and the number of haplotypes correspondingly decreased from 213 to 149. The haplotype information for both alignments and the MP and MJN analyses of the 534-bp alignment are described in Figs. S1-S7.

Marine Reservoir Effects and the Calibration of Direct Dates from El Arenal-1. Marine reservoir effects are routinely expressed as a $\Delta R$ value, which is the difference between the conventional radiocarbon age of a sample of known age from a specific locality and the equivalent age predicted by the global modeled marine calibration curve (39). Eight $\Delta R$ values are available for the west coast of South America between the equator and Cape Horn (Table S4) to calibrate the $622 \pm 35$ date for the El Arenal-1 specimen. Unfortunately, all but one of these values can be shown to be problematic for calibration purposes (Table S4), so we follow Reimer and Reimer's (13) recommendation when pooling multiple $\Delta R$ values, and take the $\Delta R$ uncertainty as the larger of the standard deviation and weighted mean measurement error. For each $\Delta R$ value, we calibrated the date for the El Arenal-1 specimen with variable marine-derived carbon content from 0 to $50 \%$ (Table 1 and Table S2) based on Ingram and Southon's (12) single bivalve determination from Valparaiso, Chile. Conventional radiocarbon ages were calibrated by using CALIB (v.5.0.1) $(15,16)$ and the Southern Hemisphere calibration dataset (SHCal04) (40) and the marine calibration model dataset (Marine04) (27). The "Mixed Marine SoHem" option was used to calibrate dates with marine and terrestrial carbon pathways.

Figs. S1-S7 and Tables S1-S4 and Table S5 and Table S6 are available in the SI.

17. Larson G, et al. (2007) Ancient DNA, pig domestication, and the spread of the Neolithic into Europe. Proc Natl Acad Sci USA 104:15276-15281.

18. Erickson DL, Smith BD, Clarke AC, Sandweiss DH, Tuross N (2005) An Asian origin for a 10,000-year-old domesticated plant in the Americas. Proc Natl Acad Sci USA 102:18315-18320.

19. Decker-Walters DS, Staub JE, Lopez-Sese A, Nakata E (2001) Diversity in landraces and cultivars of bottle gourd (Lagenaria siceraria; Cucurbitaceae) as assessed by random amplified polymorphic DNA. Genet Resources Crop Evol 48:369-378.

20. Leonard JA, et al. (2006) Animal DNA in PCR reagents plagues ancient DNA research. J Archaeol Sci 34:1361-1366.

21. Sakamoto N, et al. (2002) Concentrations of radiocarbon and isotope compositions of stable carbon in food. J Nucl Sci Technol 39:323-328.

22. Hobson KA, Clark RG (1992) Assessing avian diets using stable isotopes I: Turnover of ${ }^{13} \mathrm{C}$ in tissues. Condor 94:181-188.

23. Hobson KA, Clark RG (1992) Assessing avian diets using stable isotopes II: Factors influencing diet-tissue fractionation. Condor 94:189-197.

24. Buckner GD, Martin JH, Pierce WC, Peter AM (1922) Calcium in egg-shell formation. $J$ Biol Chem 51:51-54.

25. Fritz JC (1937) The effect of feeding grit on digestibility in the domestic fowl. Poult Sci 16:75-79.

26. Contreras L, Quiroz D, Sanchez M, Caballero C (2005) Ceramios, maices y ranas. .. un campamento El Vergel en las costas de Arauco. Actas del XVI Congreso Nacional de Arqueologia Chilena (Museo de Historia Natural de Concepcion, Direccion de Bibliotecas, Archivos y Museos, Sociedad Chilena de Arqueologia, Concepcion, Chile), pp 357-367.

27. Hughen KA, et al. (2004) MARINE04 marine radiocarbon age calibration, $0-26 \mathrm{cal} \mathrm{kyr}$ BP. Radiocarbon 46:1059-1086.

28. Athfield BN, Green RC, Craig J, McFadgen B, Bickler S (2008) Influence of marine sources on ${ }^{14} \mathrm{C}$ ages: Isotopic data from Watom Island, Papua New Guinea inhumations and pig teeth in light of new dietary standards. J R Soc N Z 38:1-23. 
29. Leach BF, Quinn C, Morrison J, Lyon G (2003) The use of multiple isotope signatures in reconstructing prehistoric human diet from archaeological bone from the Pacific and New Zealand. N Z J Archaeol 23:31-98.

30. Wilmshurst JM, Anderson AJ, Higham TFG, Worthy TH (2008) Dating the late prehistoric dispersal of Polynesians to New Zealand using the commensal Pacific rat. Proc Natl Acad Sci USA 105:7676-7680.

31. Miller SA, Dykes DD, Polesky HF (1988) A simple salting out procedure for extracting DNA from human nucleated cells. Nucleic Acids Res 16:1215.

32. Thompson JD, Gibson TJ, Plewniak F, Jeanmougin F, Higgins DG (1997) The ClustalX windows interface: Flexible strategies for multiple sequence alignment aided by quality analysis tools. Nucleic Acids Res 24:4876-4882.

33. Fumihito A, et al. (1994) One subspecies of the red junglefowl (Gallus gallus gallus) suffices as the matriarchic ancestor of all domestic breeds. Proc Natl Acad Sci USA 91:12505-12509.
34. Kumar S, Tamura K, Nei M (2004) MEGA3: Integrated software for molecular evolutionary genetics analysis and sequence alignment. Brief Bioinform 5:150-163.

35. Forster P, Harding R, Torroni A, Bandelt H-J (1996) Origin and evolution of Native American mtDNA variation: A reappraisal. Am J Hum Genet 59:935-945.

36. Swofford DL (2007) PAUP. Phylogenetic Analysis Using Parsimony (Sinauer, Sunderland, MA), Version 4.

37. Philippe $\mathrm{H}$, et al. (2004) Phylogenomics of eukaryotes: impact of missing data on large alignments. Mol Biol Evol 21:1740-1752.

38. Weins JJ (2006) Missing data and the design of phylogenetic analyses. J Biomed Inform 39:34-42.

39. Stuiver M, Kra RS (1986) Calibration issue, Proceedings of the 12 th International ${ }^{14} \mathrm{C}$ Conference. Radiocarbon 28:805-1030.

40. McCormac FG, et al. (2004) SHCAL04 southern hemisphere calibration, 0-11.0 cal kyr BP. Radiocarbon 46:1087-1092. 